\title{
Institutos de pesquisa em saúde
}

\author{
Health research institutes
}

Erney Plessmann Camargo 1

Oswaldo Augusto Sant'Anna 2

Abstract By the end of the 19th century, after the advances in surgical asepsis and the understanding of the role of microorganisms in the etiology of many infectious diseases, research institutes in the public health area were created worldwide with the objectives of undertaking "scientific research into the causes, prevention and treatment of disease in man and animals and to prepare and supply protective and curative materials such as vaccines and antitoxins". To pursue these objectives the institutes hired the best scientists from everywhere. This was an exhilarating period for research in which discoveries proliferated. After that, institutes got into depression and even insolvency. Most recovered, many not. Many are still suffering from an "identity crisis". In this paper we analyze the fate of the health research institutes in Brazil, the causes of their success and eventual failures and the possible ways to get out of their current difficulties.

Key words Research, Microorganisms, Pathogens, Infections agents, Vaccines, Anti-sera, Butantan, Manguinhos, Scientific policy, Funding and funding agencies
Resumo Ao fim do século 19, em seguida aos avanços na assepsia cirúrgica e no esclarecimento do papel de microorganismos como causadores de moléstias infecciosas, foram criados em escala mundial "institutos de pesquisa com os objetivos de conduzir pesquisa sobre as causas, prevenção e tratamento de homens e animais e de desenvolver produtos preventivos e curativos como vacinase antitoxinas". Para atingir esses objetivos os institutos recrutaram os melhores cientistas disponiveis em todos os lugares. Este foi um período fulgurante para a pesquisa sublinhado por inúmeras descobertas sobre as doenças infecciosas. Passada essa fase, os institutos entraram em depressão e até mesmo insolvência. Muitos se recuperaram, alguns não. Muitos ainda sofrem de uma "crise de identidade". Neste ensaio analisamos o destino dos institutos de pesquisa em saúde no Brasil, as causas de seu sucesso e eventuais fracassos e as medidas possíveis de ajudá-los a contornar suas presentes dificuldades.

Palavras-chave Pesquisa, Micróbios, Patógenos, Agentes infecciosos, Vacinas, Soros, Butantan, Manguinhos, Política científica, Financiamento, Agências.
1 Instituto Butantan.

Av. Vital Brazil 1500.

05503-900, São Paulo SP.

erney@cnpq.br

2 Laboratório

de Microbiologia

do Instituto Butantan. 


\section{As origens}

Os principais responsáveis pelo aumento da vida média e da expectativa de vida da humanidade, a partir do século 20, foram as descobertas sobre os agentes infecciosos e o desenvolvimento de técnicas e modos de controlá-las. Essas pesquisas foram conduzidas em institutos criados, em todo o mundo, a partir de 1890 , como as primeiras instituições públicas destinadas à pesquisa médica. Hoje dispomos de institutos, privados ou públicos, com a mais diversa vocação: institutos de pediatria, geriatria, ginecologia, cardiologia, epidemiologia, cancerologia, etc. Porém, os institutos públicos de pesquisa sobre agentes infecciosos são muito mais antigos e têm uma história centenária de pesquisa médica. Acreditamos que a análise de seu desempenho e de sua evolução ao longo do tempo possa servir de referência aos institutos públicos contemporâneos, seja para a profilaxia de erros, seja para iniciativas com chances de êxito (Brazil,1989).

A história dos agentes infecciosos e dos institutos começa nas últimas décadas do século 19. Mas, como diria George Elliot (1876), uma história sempre começa no meio (in "media res"). Isso porque seus cenários vão sendo montados ao longo do tempo, sem precisão de início. Já em 1546, embora por pura intuição, Fracastorius sustentava que as epidemias se disseminavam por meio de partículas invisíveis, levadas pelo ar, pela respiração, pelo contato direto entre pessoas. Essas "partículas invisíveis" tornaram-se visíveis depois do microscópio de Leeuwenhoek, mas só dois séculos depois, como bactérias, foram reconhecidas como possíveis agentes de doenças. Jakob Henle, que viria a ser professor de Koch, em 1840 já sustentava que os responsáveis pelas doenças infecciosas poderiam ser organismos microscópicos. Lister (Fisher, 1977), a partir de 1865 em Londres, resolveu, empiricamente, usar o fenol como desinfetante de incisões cirúrgicas e, mais tarde, durante suas operações, passou a borrifar fenol em toda a sala cirúrgica, paciente e equipe incluídos. Ao mesmo tempo, Tait, em Birmingham, apesar de ridicularizar as idéias sobre bactérias infectantes, fazia lavar escrupulosamente com água e sabão tanto a sala quanto o material cirúrgico. O sucesso dos procedimentos de ambos consolidou os princípios antissépticos antes que os agentes sépticos se tornassem conhecidos.

Enquanto isso, Pasteur (Debre \& Forster, 1998) deixava de lado a química das fermentações e embarcava no estudo de sua biologia, mostrando, a partir de 1860, que elas eram causadas por microrganismos e que organismos diferentes participavam de cada tipo de fermentação. Assim nascia a microbiologia. A seguir, Pasteur se dedicou a provar que a geração espontânea não existia e que microrganismos deveriam ser adicionados ao mosto para que fermentações e outros processos ocorressem.

A partir daí as coisas se desenrolaram com extrema rapidez. Koch (Broch, 1975) em 1876 descreveu os bacilos do antrax, ensinou como cultivá-los e demonstrou que a sua inoculação em animais reproduzia a doença. Pasteur, em seguida, descreveu os estafilococos, pneumococos e estreptococos nas infecções correspondentes. Koch descobriu o bacilo da tuberculose e o vibrião colérico. Pasteur produziu uma vacina contra a cólera, depois outra contra o carbúnculo e finalmente uma contra a raiva. Assim nasceu a imunologia, que, como sempre acontece, foi precedida por outras observações ou por alguém, no caso Jenner (1996).

Essa avalanche de descobertas criou grande excitação em todo o mundo científico aliada a um certo júbilo pela compreensão do papel dos microrganismos. Mas, ao mesmo tempo, gerou um certo senso de urgência quanto ao conhecimento e controle das doenças por elas causadas. O senso de urgência envolveu tanto autoridades quanto os segmentos educados das populações. A solução encontrada foi a de criar institutos, primeiro o de Paris, Institut Pasteur, inaugurado em 1888 e depois, em 1891, o de Londres, British Institute of Preventive Medicine, mais tarde chamado de Lister Institute e o de Berlim, das Institute für Infektionskrankheiten, mais tarde Institute Robert Koch.

Pasteur, Lister e Koch foram respectivamente diretores de cada instituto por muitos anos. Recursos para a criação do Instituto Pasteur se originaram de contribuições internacionais, enquanto os de Londres e Berlim, dos tesouros nacionais. Nos Estados Unidos, o Rockefeller Institute foi criado, em 1901, por doações pessoais de John D. Rockefeller. Esses institutos rapidamente reuniram os melhores cientistas europeus, entre os quais Roux, Metchnikoff, Kitasato, Erlich, von Bohering, e em pouco tempo revelaram ao mundo os agentes causais das principais infecções humanas e animais.

Antes de entrarmos na história da criação dos institutos e de sua participação na pesquisa em saúde no Brasil, vale a pena tirarmos algumas lições da pequena história descrita, acrescentando algumas informações. 
1) A criação dos Institutos visava atender objetiva e rapidamente a uma demanda da saúde contemporânea, ou seja, o conhecimento e controle dos agentes infecciosos.

2) Os decretos e portarias de criação dos institutos explicitavam claramente essa demanda. Como exemplo podemos citar os objetivos do British Institute: to undertake scientific research into the causes, prevention and treatment of disease in man and animals and to prepare and supply protective and curative materials such as vaccines and antitoxins. Esses objetivos, embora sob diferentes redações e com ênfases ligeiramente distintas, foram adotados por todos os três Institutos e pelos demais institutos criados em todo o mundo, inclusive no Brasil. Por exemplo, um dos objetivos iniciais do Rockefeller Institute, hoje Rockefeller University, foi o de estudar a contaminação do leite de Nova York.

3) Em todos os decretos ou atos de fundação, ficava absolutamente claro que a solução dos problemas de saúde deveria ser mediada pela pesquisa científica, ou seja, os institutos seriam essencialmente institutos de pesquisa, não institutos assistenciais. Para isso havia outros.

4) Fazia parte das atribuições dos institutos a produção de anti-soros e antitoxinas contra as bactérias e o desenvolvimento e a produção de vacinas. Ou seja, os institutos não deveriam se limitar à pesquisa, mas converter os conhecimentos adquiridos em produtos de utilidade à saúde. 5) A essas tarefas se acrescentariam as de difusão do conhecimento adquirido e de treinamento de pessoal. Desde sua fundação todos os três institutos estiveram abertos a cientistas e estudantes de todo o mundo. Dentro desse espírito, Roux ministrou, em 1889, no Pasteur, o primeiro curso de microbiologia do mundo: "Cours de microbie technique".

6) Os institutos foram criados por decisões governamentais com forte apoio da população e da opinião pública nacional e internacional.

7) Os institutos recrutaram grandes cientistas em suas áreas de atuação e foram, na origem, dirigidos por eminentes pesquisadores como Pasteur, Lister e Koch.

8) Os institutos resolveram, ou pelo menos equacionaram, os problemas que lhes foram propostos em tempo relativamente curto. Passado o período áureo de pesquisa e produção, alguns institutos entraram em hibernação, com fases de inoperância e pouca criatividade. Por várias razões perderam o brilho ofuscante das primeiras décadas e entraram em senescência prematura.

\section{As universidades}

Uma pergunta, porém, precede todas as considerações acima. Uma vez que tanto os pesquisadores quanto os diretores dos institutos eram de origem e vida universitária, por que se optou pela criação de institutos e não pela utilização das universidades para a solução dos problemas em questão? Por que todo o trabalho e custo de criar institutos, em vez de encomendar as pesquisas às universidades que eram pujantes instituições tanto na Inglaterra como na França e Alemanha?

Louis Pasteur cumpriu uma carreira acadêmica formal, inicialmente como químico, com doutorado e tudo o mais, e foi por muitos anos diretor da Ecole Normale de Paris, arquétipo da Academia francesa. Algumas vezes foi chamado a resolver problemas práticos como o da praga (pébrine) do bicho-da-seda e da fermentação da cerveja. O próprio Napoleão III pediu-lhe que estudasse os problemas da fermentação do vinho, cujas safras vinham se deteriorando a partir de 1860. Pasteur atendeu com sucesso a todas essas demandas, sem jamais deixar a Academia, vindo a deixá-la apenas para dirigir o Institut Pasteur.

Robert Koch formara-se em medicina e por muitos anos exercera a medicina privada, sendo em seguida incorporado aos serviços de saúde alemães e finalmente ingressando como professor e diretor do Instituto de Higiene na Universidade de Berlim, de onde somente saiu para dirigir o instituto de doenças infecciosas.

Joseph Lister formou-se em medicina no University College de Londres e seguiu para Edimburgo como cirurgião e depois para a Glasgow University, de onde retornou à Inglaterra, para o famosíssimo King's College. Com incontestável liderança cirúrgica percorreu, em campanha de proselitismo, todo o Império e os Estados Unidos, porém sem deixar a Academia, de onde saiu somente para dirigir o British Institute of Preventive Medicine.

Portanto, todos os três pesquisadores tinham fortes raízes acadêmicas e ocupavam posições de prestígio e comando universitário. Por que simplesmente não subsidiar seus serviços e apresentar a eles as demandas específicas da saúde?

Já se insinuou que os institutos foram criados para saciar a vaidade e o desejo de poder desses três pesquisadores. Não é verdade! Não precisavam disso. Cada um deles coletara todos os títulos honoríficos possíveis em seus países e 
fora deles. O prestígio acadêmico era enorme e o respeito de que desfrutavam em suas respectivas universidades, incomparável. Quaisquer de seus desejos seriam ordens para seus colaboradores.

Em verdade, os institutos de pesquisa em saúde foram criados fora das universidades, em parte por respeito ao etos universitário, em parte pela necessidade de resultados imediatos.

Quando os institutos de saúde foram criados, as universidades já tinham mais ou menos 10 séculos de existência. Já possuíam tradição e princípios consolidados. Todas haviam aprendido a perseguir os sagrados objetivos de geração e transmissão de conhecimentos, sem barreiras e sem compromissos com pressões externas. Todas percebiam e processavam a realidade em que viviam segundo seus métodos de perscrutação e análise. Em macro-perspectiva, sempre estiveram sintonizadas com seu tempo e sua realidade social. E todas sabiam que, em termos de sintonia com a realidade social, universidades não deveriam ser minuciosos relógios de ponto, mas tolerantes relógios solares. Todas valorizavam, acima de tudo, o progresso e a evolução desse predicado único da espécie humana que é o conhecimento, a cultura. Além disso, todas sabiam que qualquer violação de seus princípios poria em risco a evolução desse mesmo conhecimento e dessa mesma cultura. Todas se recordavam das trágicas conseqüências da violação desses princípios pela truculência política ou religiosa. Não sabiam ainda que o establishment econômico também tentaria violentá-las (nem poderiam saber, porque essa veio a ser uma ingerência recente).

Aparentemente, os dirigentes de 1890, herdeiros do enlightenment e conhecedores da importância, dos princípios e do modus operandi das universidades, resolveram poupá-las. Além disso, tinham pressa e universidades são saudavelmente lentas e rebeldes. Não é de seu papel correrem açodadas atrás de inovações tecnológicas. A elas cabe gerar os conhecimentos e os profissionais que providenciarão essas inovações. Esses profissionais, no fim do século 19, concentraram-se nos recém-criados institutos e partiram para encontrar soluções imediatas para seus problemas baseados nos conhecimentos que haviam adquirido nas universidades. Assim nasceram os Institutos de Pesquisa em Saúde.

\section{A pesquisa em saúde no Brasil}

A pesquisa em saúde no Brasil não nasce nos institutos nem nas universidades. Ela nasce na Bahia, entre professores da Escola de Medicina e médicos de clínica particular. Os nomes de Wucherer, Patterson, Silva Lima, Silva Araújo e Pirajá da Silva (Bacelar, 1963) estão ligados às primeiras descobertas exclusivamente brasileiras de agentes infecciosos como a filária (Wurchereria), o Necator e o Schistosoma mansoni.

Porém, os estudos sobre vírus e bactérias patogênicas e a produção de soros e vacinas, temas que afligiam o mundo ao fim do século 19, no Brasil, nascem com os institutos, cujos princípios e objetivos serão os mesmos que nortearam a criação dos congêneres europeus. Aliás, nascem quase ao mesmo tempo. Em 1888, por instâncias de D. Pedro II, é criado no Rio de Janeiro, vinculado à Santa Casa, o Instituto Pasteur do Brasil, com o objetivo de produzir vacina contra a raiva pelo método pasteuriano.

Porém os institutos brasileiros não brotam das universidades, em verdade as precedem.

Em 1891, o governo de São Paulo, pela lei de número 12 cria o Serviço Sanitário de São Paulo que, em 1892, passa a abrigar os laboratórios de Análises Clínicas (para o controle sanitário de alimentos), de Farmácia (para a produção de medicamentos), o de Bacteriologia e o Instituto Vacinogênico (para a produção de vacinas contra a varíola).

O Instituto de Bacteriologia, depois Bacteriológico, foi inicialmente dirigido por um enviado do próprio Pasteur, mas quem realmente o assumiu e dele tornou-se diretor foi Adolfo Lutz (Brazil, 1989), discípulo de Lister e homem intelectualmente inquieto que perambulou pelos centros de ciência do mundo inteiro, chegando até a ser chefe de um hospital para hansenianos no Havaí. A contribuição de Lutz à ciência é por demais conhecida para ser aqui repetida. O que é importante é que o Instituto Bacteriológico, sob sua direção, ganhou rapidamente o perfil dos institutos europeus. Em 1899, Lutz e o jovem assistente Vital Brazil (Pereira Neto, 2002) identificaram e caracterizaram a epidemia de peste que assolava Santos. Mas isso não bastava. Para tratar e controlar a peste era necessário produzir soros que até então eram produzidos apenas em Paris. Por ordem do secretário do Interior de São Paulo, um laboratório foi criado para a produção de soros com a participação de Emílio Ribas, Lutz, Vital Brazil e Oswaldo Cruz (Fraga, 1972; Aragão, 
1940). O local escolhido, em 1899, foi a fazenda Butantan. Em 1901, do Bacteriológico deriva o Instituto Serumterápico que se torna Instituto Butantan. Sua atribuição principal era a de produzir soros antipestosos, o que ele prontamente consegue nas estrebarias adaptadas da fazenda Butantan.

A epidemia de peste que se iniciara em Santos ameaçava atingir também o Rio de Janeiro. O governo comissionou o barão de Pedro Affonso (Fernandes, 1989), com alguma experiência na produção de vacinas contra a varíola em seu laboratório semi-particular, o Instituto Vacínico Municipal, para organizar a produção de soro antipestoso no Rio. Para a tarefa, o barão convidou Oswaldo Cruz, já bastante conhecido por sua tese sobre a veiculação microbiana pelas águas (Cruz, 1982) e que voltara recentemente de estágio no Instituto Pasteur de Paris. Dessa forma, em 1900, era criado o Instituto Soroterápico, na fazenda Manguinhos. Rapidamente, com a colaboração de Henrique Vasconcellos e de estudantes, entre os quais Ezequiel Dias, o Instituto Soroterápico passa a produzir o soro desejado. O barão e Oswaldo Cruz viveram entre confrontos polidos até que Oswaldo Cruz assumisse a direção do instituto em 1902.

\section{As decorrências}

A história dos dois institutos, Butantan e Oswaldo Cruz, tem muitas semelhanças (Benchimol \& Teixeira, 1993), mas, mais que isso, reflete a revolução na medicina experimental do início do século 20. A análise da inserção desses institutos na história da pesquisa em saúde no Brasil traz lições e informações.

1) Em primeiro lugar, é preciso esclarecer que a sociedade participou ativamente da criação dos institutos no Brasil. Um exemplo basta. A elite paulistana, congregada no exclusivo Clube Internacional, iniciou, em 1901, uma campanha pública de arrecadação para a criação, em São Paulo, de um instituto destinado ao estudo e controle da raiva por meio da produção de vacinas. Assim foi criado em 1903 o Instituto Pasteur de São Paulo. Está claro que essa era a postura das camadas diferenciadas da população capaz de perceber seus interesses além do cotidiano. A população em geral, ainda imersa em conceitos médicos arcaicos e em superstições, se oporia às campanhas vacinais e sanitárias empreendidas por Oswaldo Cruz no Rio e
Emílio Ribas em São Paulo. A lição que se pode tirar é a de que medidas essenciais na área de saúde podem ser altamente impopulares, o que não deve ser razão para descartá-las.

2) A criação dos institutos no Brasil procurou atender a necessidades explícitas da saúde no país, como exemplificado no item anterior. $\mathrm{O}$ mesmo objetivo se repetiu na criação dos dois institutos soroterápicos, o de São Paulo e o do Rio. Eles foram criados com o propósito claro, definido e específico de produzir soro antipestoso. E o fizeram com sucesso.

A experiência vivida por esses institutos tem implicações mais amplas para os institutos em geral e reproduzem o mesmo dilema vivido pelos institutos europeus: cumprida a tarefa, o que deverão fazer os institutos?

Repetir-se eternamente na mesma tarefa, tornando-se apenas uma usina produtora de insumos ou serviços?

Aguardar novas ordens? Neste caso, quem ditará as novas tarefas e ordens? O poder público? Ou será o próprio instituto que deverá descobrir e adotar novas tarefas e novos rumos?

Evidentemente, quanto mais limitada a tarefa original, mais rapidamente a pergunta se impunha.

Mais ampla a tarefa, mais tranqüila a evolução. Por exemplo, o Instituto Bacteriológico de São Paulo foi criado para realizar pesquisas em bacteriologia visando particularmente ao estudo de epidemias e epizootias e a produção de vacinas. Tarefas semelhantes tiveram o Pasteur de Paris, o Lister e o Koch. Logicamente a missão desses institutos não se esgotaria em curto prazo e novas epidemias (ou velhas) surgiriam e novas vacinas seriam necessárias. Mas institutos de missão curta se esgotariam rápido.

Oswaldo Cruz percebeu esse dilema assim que cumpriu a tarefa antipestosa, mas o barão de Pedro Affonso, não. Entraram em conflito. A causa do conflito radicava na visão distinta das duas personalidades sobre os destinos do Instituto Soroterápico. O barão favorecia a produção de soros e vacinas. Oswaldo Cruz, imbuído do espírito pasteuriano, favorecia a pesquisa microbiana senso lato, a procura de novos patógenos e de novas estratégias de combate. Era também pelo ensino e treinamento de pessoal, pilares do modelo pasteuriano. Prevaleceu Oswaldo Cruz e, em 1907, sob sua direção, o Soroterápico torna-se Instituto de Patologia Experimental, depois Instituto Oswaldo Cruz, etc. Não fora Oswaldo Cruz, e não houvesse um poder público esclarecido para apóia- 
lo, e o Soroterápico seria soroterápico até hoje, se existisse.

Com o Butantan passa-se coisa semelhante. Os soros antipestosos foram produzidos e o instituto se auto-esgotaria não fosse a diligência de Vital Brazil que ampliou o seu escopo e passou a produzir anti-soros até então inéditos na história da saúde pública: os soros antiofídicos, que haviam sido cogitados por Calmette na Indochina apenas um ano antes. $\mathrm{O}$ instituto ganhou mais algumas décadas de vida.

Outros institutos foram mais afortunados e desde o início tiveram missões mais amplas. $\mathrm{O}$ ato de criação do Instituto Biológico em São Paulo especificava: estudar e divulgar questões ligadas à defesa agrícola animal, preparar soros, vacinas e produtos terapêuticos para a proteção de rebanhos e organizar campanhas e cursos práticos sobre as pesquisas realizadas.

Porém independentemente da estreiteza ou largueza de sua proposta original, institutos podem entrar em hibernação ou estagnação por várias razões. Algumas delas são óbvias, outras mais sutis. Vale a pena examiná-las.

\section{Causas da estagnação e senescência}

Institutos são vulneráveis a muitos fatores exógenos ou endógenos.

\section{Truculência política, religiosa ou racial}

Às vésperas da Segunda Guerra Mundial, o Instituto Robert Koch foi palco de expurgos anti-semitas, enquanto no Pasteur, a mesma opressão levou notáveis pesquisadores, entre os quais Jacques Monod e François Jacob, a aderirem á resistência francesa anti-nazista. Todavia, sob esse aspecto, institutos não são mais vulneráveis que universidades. Há pouco tempo, sob a ditadura militar, a maior universidade brasileira (USP) e o maior instituto de pesquisas (Instituto Oswaldo Cruz) foram igualmente vitimas de truculência política, tendo tido vários de seus quadros cassados por Atos Institucionais (Benchimol \& Teixeira, 1993; Edusp, 1969). Porém, fica sempre a impressão de que, por serem menores, os institutos são mais vulneráveis, embora isso não seja necessariamente verdadeiro no caso da truculência política ou religiosa. No mundo subdesenvolvido há sempre um certo número de universidades sendo submetidas a expurgos e opressões a cada momento.

\section{Flutuações na qualidade dos quadros científico e funcional}

Neste tópico sim, por serem menores que as universidades, os institutos têm menor poder-tampão e pequenas alterações em seus quadros podem alterar completamente seus destinos. Lideranças, tanto científicas quanto administrativas, têm papel decisivo para a vida de um instituto. Já universidades são grandes paquidermes: se é difícil empurrá-las para a frente, também é difícil empurrá-las para trás.

Não é por acaso que o apogeu dos principais institutos europeus e brasileiros coincidiu com as gestões das grandes lideranças de Pasteur, Lister, Koch, Oswaldo Cruz e Vital Brazil. A história não registra nenhum pendor ou talento administrativo especial nessas personalidades, mas registra sua incomparável liderança científica. Em alguns casos, essas lideranças foram seguidas de outras igualmente brilhantes, o melhor exemplo sendo o de Manguinhos, onde Carlos Chagas sucede a Oswaldo Cruz.

Todavia, independentemente de lideranças, a evolução dos institutos tem um certo grau de crueldade autofágica. Passada a fase heróica em que governos e sociedades convocam os institutos para que resolvam problemas cruciais para a saúde, seu prestígio entra em declínio, aportes financeiros escasseiam, lideranças procuram posições de maior prestígio em outras instituições para onde jovens talentos também podem ser desviados. O entusiasmo dos primeiros tempos declina. Gradativamente a mediocridade ganha espaço. A corporação interna se organiza e acaba por ter grande peso dentro da instituição. A década de 1970, sob a égide da ditadura, foi madrasta para os institutos, suprimindo lideranças e promovendo mediocridades sob gestões pouco inspiradas. Mas seria bom se fosse só a ditadura a responsável pela mediocrização: teria passado. Infelizmente o ciclo não se esgota facilmente.

\section{Incapacidade de resposta a novos desafios}

O corporativismo, que foi ganhando corpo com o declínio dos institutos, atribui maior importância aos problemas internos da instituição que aos problemas reais da saúde do país em um dado momento. $\mathrm{O}$ corporativismo gera, dentro dos institutos, uma verdadeira massa inercial que até mesmo administrações iluminadas têm dificuldade em direcionar para o 
cumprimento das atividades-fim dos institutos. A ênfase desloca-se para as atividades-meio: carreiras, salários, benesses, etc.

O corporativismo não é a única causa das dificuldades dos institutos. Desvios de rumo também estão entre elas. Os institutos foram concebidos como centros de pesquisa da qual derivariam a produção de insumos e as atividades de ensino e divulgação. Esses três componentes deveriam existir em equilíbrio. A predominância exagerada de qualquer um deles pode descaracterizar qualquer instituto.

Por exemplo, a ênfase na pesquisa fundamental pode levar pesquisadores de um instituto a imitar as características das universidades, adotando cacoetes universitários de produtividade tais como número de papers, índice de impacto, etc. Essa postura os distancia dos compromissos originais da instituição com a pesquisa em saúde. Infelizmente esse tipo de desvio é potencializado por agências financiadoras de pesquisa e de pós-graduação que, em seus biased programas de avaliação, ignoram a importância e as peculiaridades da geração de conhecimento pelos institutos.

O desvio oposto é o do excessivo compromisso com a produção de insumos, que tende a converter o instituto em mera usina, perdendo aquela característica original de inovação em métodos e processos no combate às doenças. Por sinal, Vital Brazil afastou-se da direção do instituto em 1919, em meio a confronto com Artur Neiva, pela seguinte razão principal, literalmente expressa em seu relatório: (O instituto) ...seria transformado em uma fábrica não só de soros, vacinas e outros produtos biológicos, como também de solutos medicamentosos, pílulas, comprimidos, etc. (Brazil, 1924). No confronto com Neiva, Vital Brazil não tinha razão total, mas esta é uma outra história (Benchimol \& Teixeira, 1993).

O corporativismo, as dificuldades administrativas naturais ou as resultantes da incompetência, a diminuição da qualidade dos quadros e os desvios de rumo são fatores que, se atuarem em conjunto por longo tempo, podem levar um instituto à paralisia funcional e à perda da sensibilidade para os novos problemas do panorama sanitário em que estão inseridos. Em conseqüência, o instituto passa a não responder às demandas reais da sociedade.

Um pequeno exemplo serve para ilustrar essa assertiva.

Os grandes institutos do mundo, os mesmos que outrora resolveram os maiores pro- blemas de saúde pública no fim do século 19, assistiram pasmos e perplexos, um século depois, o gigantesco desafio da Aids. Apenas o Instituto Pasteur, que havia passado por recente revolução interna sob a direção de Monod na esteira da biologia molecular, pôde responder aos desafios por meio das descobertas de Montagnier. Os demais institutos apenas fizeram eco às descobertas de instituições mais jovens, em geral norte-americanas.

Os institutos de pesquisa brasileiros vêm respondendo com igual timidez aos desafios contemporâneos da dengue, e das sempre presentes endemias brasileiras como a malária, as leishmanioses ou as doenças emergentes como borrelioses, riquetsioses e novas viroses. Embora dispondo de quadros da melhor qualidade nessas áreas, falta à pesquisa dos institutos a objetividade necessária para a transformação do conhecimento em insumos.

Neste momento, uma das maiores dificuldades dos institutos de pesquisa em saúde, senso lato, é a de redefinir seus objetivos. Porém, a pergunta que se põe é quem redefine esses objetivos. No século 19 as diretrizes foram dadas pelas sociedades e governos, tanto no mundo quanto no Brasil. E hoje, no Brasil?

Soluções acabam aparecendo e se impondo, mas, como todo o sistema vive em regime de alta entropia, as soluções acabam surgindo por caminhos tortuosos. Um bom exemplo foi a criação do programa de auto-suficiência em imunobiológicos do país. A partir da década de 1980, o país cogitou de tornar-se independente da importação de soros e vacinas e lentamente foi criando um modelo de auto-suficiência para a produção desses insumos. Graças a esse modelo, Manguinhos e Butantan puderam desenvolver suas usinas a ponto de atender a demanda do país em vacinas bacterianas e virais. A resposta desses institutos ao programa foi exemplar e altamente eficiente, não só modernizando sua produção como produzindo vacinas novas (Raw et al., 2002). A continuação do programa certamente garantirá ao país, em uma década, autonomia completa na produção de soros e vacinas e total independência da produção estrangeira. Todavia o programa não foi a resultante de uma decisão central única e claramente estabelecida. Lideranças dos dois institutos e setores diversos da área de saúde, ao longo de muito tempo, exerceram todo tipo de pressão e persuasão sobre governos sucessivos, tanto para a criação como manutenção e ampliação do programa. 
A necessidade desse tipo de ação conjunta reflete a carência, por parte dos governos, de um entendimento claro do papel dos institutos. Governos não percebem o enorme potencial dos institutos na implantação de programas e projetos na área de ciência e tecnologia, seja em saúde seja em qualquer outra área do conhecimento. Institutos são muito mais ágeis que as universidades para a condução de ações aplicadas e para fins imediatos: são ágeis parceiros para inovações tecnológicas (Camargo, 2002). Foram concebidos para isso. Se bem dirigidos adaptam-se aos sempre variáveis panoramas das emergências sociais. Em vez de apro- veitarem essa peculiar flexibilidade potencial das centenas de institutos (de todas as áreas) existentes no país, governos, ou grupos dentro de governos, se especializam em cobrar das universidades ações pontuais e soluções técnicas que não lhes cabe prover.

Para o futuro, esperemos que a existência de agências ministeriais de C\&T e a integração entre elas a um programa geral do Conselho Nacional de C\&T possa traçar diretrizes para a saúde (e outras áreas) e comprometer definitivamente os institutos com ações pragmáticas de interesse da nação. A matéria-prima, e de boa qualidade, está aí, à disposição.

\section{Referências bibliográficas}

Aragão HB 1940. Oswaldo Cruz e a Escola de Manguinhos. Bedeschi, Rio de Janeiro. (Conferência realizada na Faculdade de Medicina de São Paulo a convite do Centro Acadêmico Oswaldo Cruz, CAOC).

Bacelar RC 1963. Brazil's contribution to tropical medicine and malaria. Gráfica Olympica Ed., Rio de Janeiro.

Benchimol J \& Teixeira LA 1993. Cobras, lagartos e outro bichos. Ed. UFRJ, Rio de Janeiro.

Brazil OV 1989. Contribuição para a história da ciência no Brasil. Casa de Vital Brasil Ed., Belo Horizonte.

Brazil V 1924. Relatório do Instituto Soroterápico de Butantã. Museu Histórico do Instituto Butantã.

Broch TD 1975. Robert Koch: a life in medicine and bacteriology. ASM Press, EUA.

Camargo EP 2002. Institutos: ágeis parceiros de C\&T Ciência e Cultura 2:4-5.

Cruz O 1982. A veiculação bacteriana pelas águas. Tese apresentada à Faculdade de Medicina do Rio de Janeiro.

Debre P \& Forster E 1998. Louis Pasteur. Johns Hopkins University Press, EUA.

Edusp 1969. O livro negro da USP. Edusp, São Paulo.

Elliot G 1876. Daniel Deronda. Wiliam Blackwood Ed., Edimburgo-Londres.
Fernandes TM 1989. Oswaldo Cruz X Barão de Pedro Affonso: polêmica no controle de imunizantes. Cadernos da Casa de Oswaldo Cruz 1.

Fisher RB 1977. Joseph Lister, 1827-1912. Stein \& Day Eds. Londres.

Fraga C 1972. Vida e obra de Oswaldo Cruz. José Olímpio Ed. Rio de Janeiro.

Jenner E 1996. Vaccination against smallpox. In Greta Mind Series Prometheus Books, EUA.

Lent \& Herman 1978. O massacre de Manguinhos. Avenir Ed., Rio de Janeiro.

Pereira Neto AF 2002. Vital Brazil. Obra Cientifica Completa. Instituto Vital Brazil Ed., Rio de Janeiro.

Raw I, Bus P, Camargo EP \& Homma A 2002. Presidenciáveis, soros e vacinas. Folha de S. Paulo, 29.9.2002, p. 3 .

Artigo apresentado em 8/12/2003

Aprovado em 17/2/2004

Versão final apresentada em 2/3/2004 